\title{
Psychometric properties of the Patient Assessment of Chronic Illness Care measure (PACIC-5A) among patients with obesity
}

\author{
Maria Schwenke ${ }^{1 *}$, Franziska D. Welzel', Claudia Luck-Sikorski ${ }^{1,2,3}$, Alexander Pabst', Anette Kersting ${ }^{4}$, \\ Matthias Blüher ${ }^{2}$, Hans-Helmut König ${ }^{5}$, Steffi G. Riedel-Heller ${ }^{1,6}$ and Janine Stein ${ }^{1}$
}

\begin{abstract}
Background: The Patient Assessment of Chronic Illness Care (PACIC-5A) was developed to assess the satisfaction with patient-provider interaction based on the Chronic Care Model. The additional 5A approach (assess, advise, agree, assist, arrange) allows to score behavioral counseling. The aim of the study was to assess the psychometric properties of the German adaptation of the PACIC-5A questionnaire in a sample of general practitioners (GP) patients with obesity.

Methods: Analyses were based on data from the study "Five A's counseling in weight management of obese patients in primary care: a cluster randomized controlled trial (INTERACT)". Data were collected via standardized questionnaires containing the 26-item version of the PACIC-5A questionnaire. A total of 117 patients with obesity were included in the analyses. Statistical procedures comprised descriptive analyses, the calculation of Cronbach's alpha, test-retest analyses and factor analyses in order to assess the psychometric properties including reliability and validity of the PACIC-5A.

Results: The patient's mean age was 43.4 years and the sample was mostly female (59\%). Middle educational level was found for the majority (78\%) and the mean Body Mass Index was $38.9 \mathrm{~kg} / \mathrm{m}^{2}$. Descriptive analyses revealed a mean PACIC score of 2.33 and 5A sum score of 2.29. Notable floor effects were found. PACIC-5A showed high level of internal consistency (Cronbach's alphas $>0.9$ ) and exploratory factor analyses resulted in a unidimensional structure.

Conclusion: The results of this study provide evidence regarding the psychometric properties of the German version of the PACIC-5A used in a sample of GP patients with obesity and make an important contribution to the reliable and valid assessment of the patient-GP interaction with regard to obesity counseling in primary care.
\end{abstract}

Keywords: Obesity, Primary care, Validity, Reliability, 5A counseling, PACIC

\section{Background}

An increase in prevalence of chronic diseases is observed worldwide. According to the World Health Organization (WHO), obesity is one chronic non-communicable disease whose worldwide prevalence nearly tripled over the last 40 years [1]. In European regions, 23\% of women and 20\% of men are obese [2]. While the management of chronic diseases is mainly based on primary health care, general

\footnotetext{
* Correspondence: Maria.Schwenke@medizin.uni-leipzig.de

${ }^{1}$ Institute of Social Medicine, Occupational Health and Public Health, Medical Faculty, University of Leipzig, Leipzig, Germany

Full list of author information is available at the end of the article
}

practitioners (GPs) treat patients with obesity on a regular basis and are responsible for both initial and long-term care. Improving the quality of the patient-GP interaction regarding obesity management is a key element for successful treatment of patients with obesity in general practice.

The Chronic Care Model (CCM) was developed for supporting and improving patient-centered primary care [3]. This multidimensional framework is based on six key dimensions: organization of health care, community resources, self-management-support, delivery system design, decision support and clinical information systems $[3,4]$. On this basis, Glasgow et al. developed the

(c) The Author(s). 2019 Open Access This article is distributed under the terms of the Creative Commons Attribution 4.0 International License (http://creativecommons.org/licenses/by/4.0/), which permits unrestricted use, distribution, and reproduction in any medium, provided you give appropriate credit to the original author(s) and the source, provide a link to the Creative Commons license, and indicate if changes were made. The Creative Commons Public Domain Dedication waiver (http://creativecommons.org/publicdomain/zero/1.0/) applies to the data made available in this article, unless otherwise stated. 
20-item self-administered Patient Assessment of Chronic Illness Care (PACIC) to assess the satisfaction with patient-provider interaction from the patient's perspective [5]. The authors predefined five subscales based on the CCM and evaluated PACICs' reliability and validity among patients with at least one chronic illness. Reliability was satisfying and results of the confirmatory factor analysis (CFA) confirmed the predefined structure with moderate goodness of fit [5]. In recent years, the instrument has been translated into several languages, including German, Spanish, Dutch, Danish and French and several studies investigated the psychometric properties among patients with different chronic diseases such as diabetes, arthritis, hypertension and chronic obstructive pulmonary disease [6-10]. Overall, PACIC investigations suggested acceptable reliability but structure validity through CFA and exploratory factor analysis (EFA) showed conflicting results. While few studies supported the five-factor structure $[6,7,10]$, others could not confirm it $[9,11-15]$.

The patient-centered "5As" (assess, advise, agree, assist, arrange) model represents an evidence-based approach of behavioral counseling $[16,17]$. Congruent with the CCM, the 5As are used to improve self-management support [18].The approach was originally developed for smoking cessation counseling. Nowadays, it has been adapted and used for different dependency-related conditions and chronic diseases including obesity [19]. The PACIC-5A represents an advanced version of the PACIC and was extended by six items to assess the $5 \mathrm{~A}$ model according to the recommendations of the US Preventive Services Task Force forming five subscales reflecting CCM as well as further five subscales reflecting the 5As and total scores [18]. Glasgow et al. evaluated the PACIC-5A questionnaire among diabetic patients. Internal consistency showed good results for the $5 \mathrm{~A}$ summary score $(\alpha>0.9)$ and adequate variability and distribution of the scales were shown. However, investigations of construct validity of the PACIC-5A are pending [18]. Recently, a study in Germany examined psychometric properties of PACIC-5A including construct validity through EFA [10]. While the structure as proposed by Glasgow et al. was confirmed, no detailed results of the factor analysis were shown in this study [10]. Other previous studies used the PACIC-5A to evaluate chronic care, especially for diabetic and asthmatic patients [20-23]. However, little is known about the underlying structure of the instrument so far.

Taken together, previous studies showed inconsistent results with regard to the psychometric properties of PACIC and only two studies evaluated PACIC-5A with gaps in analyses of the construct validity. Further, PACIC and PACIC-5A was mostly used and validated in samples of diabetic patients. So far, little is known about the psychometric quality of the PACIC-5A used in patients with obesity. Thus, the aim of the current study was to conduct a psychometric analysis of the German adaptation of the PACIC-5A scale in a sample of patients with obesity in primary care.

\section{Methods \\ Study design and sample}

This methodological study used data from the study "Five A's counseling in weight management of patients with obesity in primary care: A cluster-randomized controlled trial (INTERACT)" [24]. The INTERACT study is a cluster-randomized controlled trial aiming at the implementation and evaluation of the internet-based learning program "5A Adipositas Management" (The 5A's of obesity management) in order to improve weight counseling within the German primary health care setting. Participants were assessed at baseline assessment (BL) and two follow-up (FU) assessments after 6 and 12 months. In addition, data from general practitioners (GP) were collected at baseline and after 12 months. Patients were recruited via GPs within their practices during consultation following specific inclusion criteria: (1) Body Mass Index (BMI) equal or greater than $30 \mathrm{~kg} / \mathrm{m}^{2}$, (2) age between 18 and 60 years and (3) German as native language. Patients were excluded from participation if acute physical or mental illnesses required priority management and made study participation impossible according to the attending GP. More detailed information of the INTERACT study has been reported elsewhere [24].

For the project, 160 subjects from 39 general practices in Central Germany were recruited. 25 patients were excluded because of BMI $<30 \mathrm{~kg} / \mathrm{m}^{2}(n=6)$, Age $>60$ years $(n=10)$, no baseline response $(n=7)$ and two patients had an acute illness that needed priority management, thus the sample at BL included 135 patients. In the current study, further 18 (13.3\%) patients were excluded from the sample because of missing values in the PACIC-5A questionnaire. All analyses of this study were based on a sample of 117 patients at BL. The sample selection process is shown in Fig. 1.

\section{Procedure and instruments}

Following the given criteria for inclusion and exclusion, the patients were selected by GPs and asked to take part in the study. Written informed consent and basic patient information was obtained from participants and sent back to the research staff. After receiving the documents, standardized self-rating questionnaires were sent to patients by postal mail. The patients were asked to complete all questionnaires at home and sent it back to the study center. The collection of data covered sociodemographic variables including age, gender, weight/ height, and education (low, middle, high) according to 


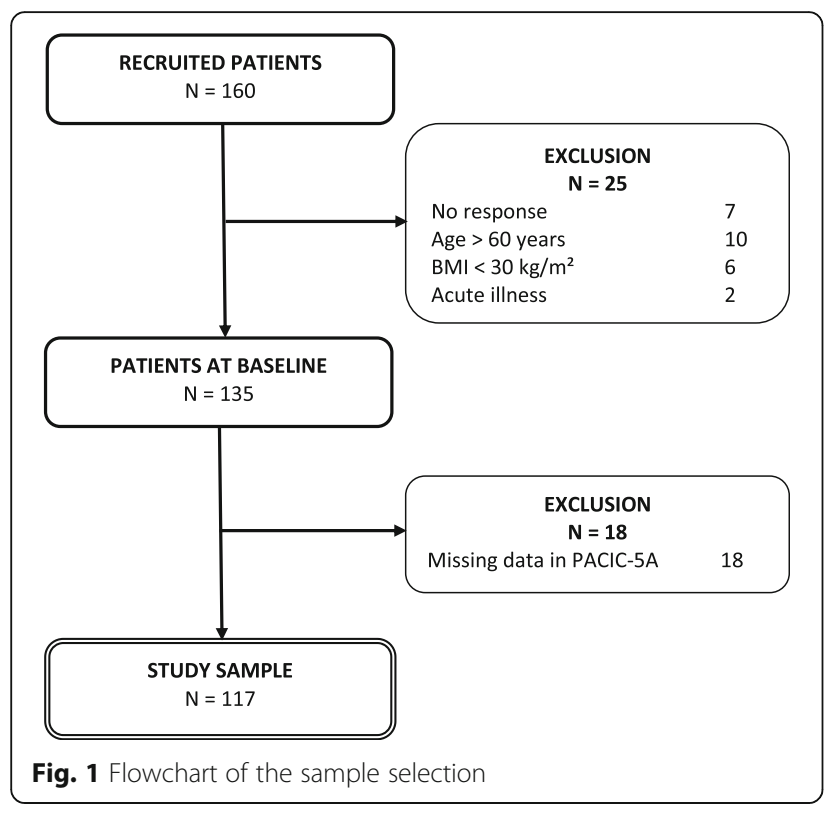

the new CASMIN educational classification [25]. The patient-physician interaction regarding obesity management was assessed by using the German adaptation of the Patient Assessment of Chronic Illness Care (PACIC-5A), which is an instrument to estimate the quality of chronic illness care according to the CCM [18]. Additionally, the PACIC-5A can be used to assess the model for behavior counseling called " $5 \mathrm{~A}$ ". It includes 26 items that can be scored on a 5-point Likert scale ranging from " $1=$ Almost never" to " $5=$ Almost always". The first 20 items of the PACIC-5A can be aggregated into five subscales based on the key components of the CCM: Patient Activation (Items 1-3), Delivery System Design/Decision Support (Items 4-6), Goal Setting (Items 7-11), Problem-solving/Contextual Counseling (Items 12-15), Follow-up/Coordination (Items 16-20) and an overall PACIC score. By including the further six items, the instrument can also be grouped into the $5 \mathrm{~A}$ summary score as well as five subscales that cover elements of the 5A approach: Assess (Item 1, 11, 15, 20, 21), Advise (Item 4, 6, 9, 19, 24), Agree (Item 2, $3,7,8,25)$, Assist (Item 10, 12, 13, 14, 26), Arrange (16, $17,18,22,23)$. In addition, for each patient specific data including comorbidities and height/weight were collected via standardized GP questionnaires. The study was approved by the ethic committee of the University of Leipzig and written informed consent was collected from all participants.

\section{Statistical analyses}

The data analyses were conducted using SPSS Statistics 24.0 (Statistical Package for Social Science Inc., IBM ${ }^{\circ}$, Chicago, IL). The overall PACIC score was calculated as the mean value of the first 20 items; the $5 \mathrm{~A}$ summary score was the mean value of items $1-4$ and $6-26$. Each subscale was scored by averaging them across the corresponding items as described previously [18]. Scores can range from 1 to 5 and higher scores indicate a higher quality of chronic illness care from patient's perspective. Statistical procedures comprised descriptive analyses of patient characteristics and the PACIC-5A items, subscales and total scores including means, standard deviations or absolute and relative frequencies with percentages, as appropriate. Floor and ceiling effects of the PACIC-5A were analyzed via the response rates of the lowest or highest possible category. Associations between the overall PACIC and $5 \mathrm{~A}$ summary scores and patient characteristics were analyzed via Pearson product-moment correlation and Spearman's rank correlation, as appropriate. In order to assess aspects of reliability, test-retest reliability by using Intraclass Correlation Coefficient (ICC) and Cronbach's alpha were calculated for the total scores and the subscales. Acceptable values for Cronbach's alpha range from 0.70 to 0.95 [26]. Exploratory factor analysis with principal component analysis was conducted in order to analyze the structure of the questionnaire and the construct validity. Prior to factor analysis, tests of multicollinearity (Bartlett test of sphericity with $p$-value $<0.05$ ) were run and sampling adequacy was calculated (Kaiser-Meyer-Olkin-criterion $(\mathrm{KMO}) \geq 0.50)$ in order to examine criteria of feasibility. The number of factors was determined by using eigenvalue $>1$ (Kaiser criterion), scree plot and parallel analysis (PA) following O'Connor's SPSS syntax [27]. We used oblique (promax) rotation where more than one factor was identified. Additionally we conducted a confirmatory factor analyses (CFA) to test the predefined factor structure with maximum likelihood estimation method. The model fit was tested using Comparative Fit Index (CFI; acceptable fit $\geq 0.95$ ), Root Mean Square Error of Approximation (RMSEA; acceptable fit $\leq 0.06$ ) and Standardized Root Mean Residual (SRMR, acceptable fit $\leq 0.08$ ) [28]. The CFA were performed using Stata 15.1 MP (Stata Corp LP, College Station, TX). Statistical significance was assumed at $p$-value $\leq 0.05$ for all computations.

\section{Results}

In Table 1, characteristics of the patient sample are displayed. Mean age of patients was 43.4 $(\mathrm{SD}=10.7)$ years ranging from 20 to 60 years. The majority of the sample was female (59\%) and had middle educational level (66.7\%). The mean BMI was $38.9 \pm 6.0 \mathrm{~kg} / \mathrm{m}^{2}$, whereas $27 \%$ of the patients were classified as obese class I (BMI $30.0-34.9 \mathrm{~kg} / \mathrm{m}^{2}$ ), $39 \%$ as obese class II (BMI 35.0-39.9 $\left.\mathrm{kg} / \mathrm{m}^{2}\right)$ and $34 \%$ as obese class III (BMI $\left.>40 \mathrm{~kg} / \mathrm{m}^{2}\right)$ according to the WHO classification [29]. The average number of comorbidities according to the GPs was $4.6 \pm$ 3.2 in addition to obesity. 
Table 1 Patient characteristics $(N=117)$

\begin{tabular}{|c|c|}
\hline Characteristics & Values \\
\hline Age in years, Mean (SD) & $\begin{array}{l}43.4(10.7) \\
\text { Range 20-60 }\end{array}$ \\
\hline \multicolumn{2}{|l|}{ Sex, n (\%) } \\
\hline Male & $48(41.0)$ \\
\hline Female & $69(59.0)$ \\
\hline \multicolumn{2}{|l|}{ Education ${ }^{\mathrm{a}}, \mathrm{n}(\%)$} \\
\hline Low & $28(23.9)$ \\
\hline Middle & $78(66.7)$ \\
\hline High & $11(9.4)$ \\
\hline BMI in kg/m², Mean (SD) & $\begin{array}{l}38.9(6.0) \\
\text { Range 30.4-56.6 }\end{array}$ \\
\hline \multicolumn{2}{|l|}{ BMI classification ${ }^{\mathrm{b}}, \mathrm{n}(\%)$} \\
\hline Obesity class I (30-35.9 kg/m²) & $32(27.0)$ \\
\hline Obesity class II (35-39.9kg/m²) & $45(39.0)$ \\
\hline Obesity class III (> 40 kg/m²) & $40(34.0)$ \\
\hline Number of comorbidities, Mean (SD) & $\begin{array}{l}4.6(3.2) \\
\text { Range 0-14 }\end{array}$ \\
\hline
\end{tabular}

$B M I$ Body Mass Index, SD standard deviation, a education classification according CASMIN classification, ${ }^{b}$ BMI classification according World Health Organization

To assess associations between the patient characteristics and the overall PACIC and 5A summary scores correlations were calculated (Table 2). In almost all cases the correlation coefficients were close to zero. Weak negative correlation was observed between the scores and BMI $(r(\mathrm{PACIC})=-0.140, r(5 \mathrm{~A})=-0.138)$. The number of comorbidities $(\mathrm{r}(\mathrm{PACIC})=0.136, \mathrm{r}(5 \mathrm{~A})=0.128)$ were slightly positive correlated with the scores, but none of these correlations were significant (Table 2).

Table 3 shows the descriptive statistics and the results of the item and scale analyses of the PACIC-5A scores as proposed by Glasgow et al. [18]. Descriptive analyses revealed a mean overall PACIC score of $2.33 \pm 0.8$ with individual PACIC items ranging from $1.42 \pm 0.9$ (Item 9) to $3.46 \pm 1.3$ (Item 5). The predefined PACIC subscales

Table 2 Correlations between overall PACIC score and 5A summary score with patient characteristics $(N=117)$

\begin{tabular}{|c|c|c|c|c|}
\hline & \multicolumn{2}{|c|}{ Overall PACIC score } & \multicolumn{2}{|c|}{ 5A summary score } \\
\hline & $\mathrm{Rho}^{\mathrm{a}}$ & $p$-value & $\mathrm{Rho}^{\mathrm{a}}$ & $p$-value \\
\hline Age & -0.089 & 0.338 & -0.093 & 0.317 \\
\hline Sex & 0.078 & 0.400 & 0.084 & 0.370 \\
\hline Education & -0.072 & 0.443 & -0.064 & 0.493 \\
\hline BMI & -0.140 & 0.133 & -0.138 & 0.136 \\
\hline BMI classification & -0.095 & 0.311 & -0.094 & 0.311 \\
\hline Number of comorbidities & 0.136 & 0.145 & 0.128 & 0.169 \\
\hline
\end{tabular}

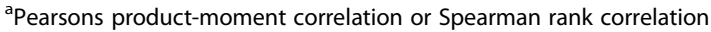
as appropriate varied from $2.08 \pm 0.9$ (Follow-up/coordination) to 2.77 \pm 1.0 (Delivery system/Decision Support).

The mean $5 \mathrm{~A}$ summary score was $2.29 \pm 0.9$ with individual $5 \mathrm{~A}$ items ranging from $1.42 \pm 0.9$ (Item 9) to $3.28 \pm 1.4$ (Item 24). Grouped into the 5A subscales values between $1.99 \pm 0.9$ (Assist) to $2.67 \pm 1.1$ (Agree) were observed.

Floor effects for overall PACIC score and 5A summary score were $5.1 \%$ in each case and no ceiling effects were detected. For individual items the percentage of persons who used the lowest answering category ("almost never") ranged from 14.5 to $76.9 \%$ and was in 23 of 26 items above $20 \%$. The percentage of persons who used the highest answering category ("almost always") ranged from 1.7 to $26.5 \%$ at item level and was in two items above $20 \%$. Internal consistency in terms of Cronbach's alpha achieved 0.93 for the overall PACIC score and 0.94 for the $5 \mathrm{~A}$ summary score. For the individual subscales Cronbach's alpha ranged from $0.68-0.89$ and reached mostly the threshold of 0.70 . An exception was the 5A Arrange subscale with an alpha just below the threshold (0.68). The correlation between individual items and the referring scale (item-scale correlation) varied from $r=0.13$ to 0.83 and was in items of two PACIC subscales and two $5 \mathrm{~A}$ subscales under the rule-of-thumb minimum value of 0.4 (Patient activation, Follow-up/ Coordination, Assist and Arrange). The correlation between individual items and the total scores (item-total correlation) was in almost all items over 0.4. Only item 16 had values below 0.3 for overall PACIC score and 5A summary score. Cronbach's alpha if item 16 deleted changed marginally from 0.925 to 0.927 for overall PACIC score and from 0.944 to 0.946 for $5 \mathrm{~A}$ summary score. To assess test-retest reliability, ICCs were measured in a sample of 56 patients six month after baseline survey. ICC for overall PACIC score was 0.57 and ranged from 0.30 to 0.60 for the subscales. Test-retest reliability for the $5 \mathrm{~A}$ scales reached higher values with 0.63 for $5 \mathrm{~A}$ summary score and 0.50 to 0.69 for the subscales. In addition, we presented the values of the two measurement times of the total scores in a scatter plot and calculated pearson's correlation (Fig. 2). The values of pearson's correlation are comparable to the ICCs $(\mathrm{r}(\mathrm{PACIC})=0.56 ; \mathrm{r}(5 \mathrm{~A})=0.62)$.

The criteria of feasibility of factor analysis showed good fit (Bartlett tests of sphericity $p=0.000, \mathrm{KMO}(\mathrm{PACIC})=$ 0.888 , KMO $(5 \mathrm{~A})=0.895)$. The Kaiser-Meyer-Olkin measure of each item revealed values above 0.7 , which is shown in Table 4. Factor analysis with eigenvalue criterion identified four factors. Factor loadings after promax rotation for the four factors are shown in the Additional file 1: Table S1 and S2. However, scree-plot and parallel analysis showed one factor structures in each case (Fig. 3). Furthermore a content analysis of the four factors did not provide a meaningful structure of the underlying concepts, so that the one 
Table 3 Descriptive items and scale characteristics $(N=117)$

\begin{tabular}{|c|c|c|c|c|c|c|c|}
\hline Scales & Mean (SD) & $\begin{array}{l}\text { Floor effects } \\
\text { n (\%) }\end{array}$ & Ceiling effects $n(\%)$ & $\begin{array}{l}\text { Item-scale- } \\
\text { correlation }^{\text {a }}\end{array}$ & $\begin{array}{l}\text { Item-total- } \\
\text { correlation }^{\text {b }}\end{array}$ & $a$ & $\begin{array}{l}\text { Test- retest } \\
\text { ICC }(n=56)\end{array}$ \\
\hline Overall PACIC Score & $2.33(0.8)$ & $6(5.1)$ & - & & & 0.93 & 0.57 \\
\hline Patient Activation & $2.70(1.1)$ & $10(8.5)$ & $3(2.6)$ & & & 0.72 & 0.46 \\
\hline Item 1 & $2.88(1.4)$ & $27(23.1)$ & $19(16.2)$ & 0.63 & 0.73 & & \\
\hline Item 2 & $2.50(1.4)$ & $40(34.2)$ & $12(10.3)$ & 0.66 & 0.66 & & \\
\hline Item 3 & $2.72(1.5)$ & $37(31.6)$ & $18(15.4)$ & 0.37 & 0.52 & & \\
\hline Delivery System/ Decision Support & $2.77(1.0)$ & $13(11.1)$ & $2(1.7)$ & & & 0.71 & 0.30 \\
\hline Item 4 & $1.82(1.2)$ & $70(59.8)$ & $4(3.4)$ & 0.40 & 0.49 & & \\
\hline Item 5 & $3.46(1.3)$ & $17(14.5)$ & $28(23.9)$ & 0.60 & 0.64 & & \\
\hline Item 6 & $3.03(1.2)$ & $20(17.1)$ & $14(12.0)$ & 0.59 & 0.59 & & \\
\hline Goal Setting/ Tailoring & $2.11(0.9)$ & $22(18.8)$ & - & & & 0.75 & 0.46 \\
\hline Item 7 & $2.94(1.4)$ & $28(23.9)$ & $20(17.1)$ & 0.69 & 0.74 & & \\
\hline Item 8 & $2.69(1.4)$ & $35(29.9)$ & $15(12.8)$ & 0.66 & 0.71 & & \\
\hline Item 9 & $1.42(0.9)$ & $89(76.1)$ & $2(1.7)$ & 0.40 & 0.50 & & \\
\hline Item 10 & $1.79(1.2)$ & $72(61.5)$ & $5(4.3)$ & 0.40 & 0.45 & & \\
\hline Item 11 & $1.71(1.1)$ & $75(64.1)$ & $3(2.6)$ & 0.43 & 0.45 & & \\
\hline Problem Solving/ Contextual & $2.28(1.2)$ & $28(23.9)$ & $2(1.7)$ & & & 0.89 & 0.59 \\
\hline Item 12 & $2.67(1.5)$ & $40(34.2)$ & $15(12.8)$ & 0.72 & 0.79 & & \\
\hline Item 13 & $1.82(1.1)$ & $66(56.4)$ & $3(2.6)$ & 0.71 & 0.71 & & \\
\hline Item 14 & $2.14(1.3)$ & $55(47.0)$ & $7(6.0)$ & 0.83 & 0.78 & & \\
\hline Item 15 & $2.50(1.4)$ & $42(35.9)$ & $11(9.4)$ & 0.77 & 0.76 & & \\
\hline Follow-up/ Coordination & $2.08(0.9)$ & $22(18.8)$ & - & & & 0.70 & 0.60 \\
\hline Item 16 & $1.57(1.1)$ & $88(75.2)$ & $6(5.1)$ & 0.13 & 0.28 & & \\
\hline Item 17 & $2.27(1.3)$ & $47(40.2)$ & $10(8.5)$ & 0.46 & 0.50 & & \\
\hline Item 18 & $2.09(1.4)$ & $63(53.8)$ & $12(10.3)$ & 0.53 & 0.53 & & \\
\hline Item 19 & $1.92(1.3)$ & $69(59.0)$ & $10(8.5)$ & 0.66 & 0.51 & & \\
\hline Item 20 & $2.55(1.6)$ & $50(42.7)$ & $19(16.2)$ & 0.52 & 0.54 & & \\
\hline 5A Summary Score & $2.29(0.9)$ & $6(5.1)$ & - & & & 0.94 & 0.63 \\
\hline Assess & $2.45(1.0)$ & $14(12.0)$ & - & & & 0.80 & 0.57 \\
\hline Item 1 & $2.88(1.4)$ & $27(23.1)$ & $19(16.2)$ & 0.61 & 0.72 & & \\
\hline Item 11 & $1.71(1.1)$ & $75(64.1)$ & $3(2.6)$ & 0.40 & 0.47 & & \\
\hline Item 15 & $2.50(1.4)$ & $42(35.9)$ & $11(9.4)$ & 0.69 & 0.78 & & \\
\hline Item 20 & $2.55(1.6)$ & $50(42.7)$ & $19(16.2)$ & 0.53 & 0.55 & & \\
\hline Item 21 & $2.62(1.4)$ & $36(30.8)$ & $13(11.1)$ & 0.69 & 0.78 & & \\
\hline Advise & $2.29(0.8)$ & $10(8.5)$ & - & & & 0.70 & 0.54 \\
\hline Item 4 & $1.82(1.2)$ & $70(59.8)$ & $4(3.4)$ & 0.40 & 0.46 & & \\
\hline Item 6 & $3.03(1.2)$ & $20(17.1)$ & $14(12.0)$ & 0.51 & 0.58 & & \\
\hline Item 9 & $1.42(0.9)$ & $89(76.1)$ & $2(1.7)$ & 0.46 & 0.50 & & \\
\hline Item 19 & $1.92(1.3)$ & 69 (59.0) & $10(8.5)$ & 0.41 & 0.52 & & \\
\hline Item 24 & $3.28(1.4)$ & 20 (17.1) & $31(26.5)$ & 0.51 & 0.74 & & \\
\hline Agree & $2.67(1.1)$ & $9(7.7)$ & $1(0.9)$ & & & 0.84 & 0.55 \\
\hline Item 2 & $2.50(1.4)$ & $40(34.2)$ & $12(10.3)$ & 0.63 & 0.67 & & \\
\hline Item 3 & $2.72(1.5)$ & 37 (31.6) & 18 (15.4) & 0.44 & 0.53 & & \\
\hline Item 7 & $2.94(1.4)$ & $28(23.9)$ & $20(17.1)$ & 0.73 & 0.75 & & \\
\hline
\end{tabular}


Table 3 Descriptive items and scale characteristics $(N=117)$ (Continued)

\begin{tabular}{|c|c|c|c|c|c|c|c|}
\hline Scales & Mean (SD) & $\begin{array}{l}\text { Floor effects } \\
\text { n (\%) }\end{array}$ & Ceiling effects n (\%) & $\begin{array}{l}\text { Item-scale- } \\
\text { correlation }\end{array}$ & $\begin{array}{l}\text { Item-total- } \\
\text { correlation }\end{array}$ & a & $\begin{array}{l}\text { Test- retest } \\
\text { ICC }(n=56)\end{array}$ \\
\hline Item 8 & $2.69(1.4)$ & $35(29.9)$ & $15(12.8)$ & 0.71 & 0.71 & & \\
\hline Item 25 & $2.50(1.4)$ & $42(35.9)$ & $11(9.4)$ & 0.73 & 0.76 & & \\
\hline Assist & $1.99(0.9)$ & $31(26.5)$ & - & & & 0.81 & 0.50 \\
\hline Item 10 & $1.79(1.2)$ & $72(61.5)$ & $5(4.3)$ & 0.39 & 0.45 & & \\
\hline Item 12 & $2.67(1.5)$ & $40(34.2)$ & $15(12.8)$ & 0.72 & 0.82 & & \\
\hline Item 13 & $1.82(1.1)$ & $66(56.4)$ & $3(2.6)$ & 0.73 & 0.72 & & \\
\hline Item 14 & $2.14(1.3)$ & $55(47.0)$ & $7(6.0)$ & 0.74 & 0.80 & & \\
\hline Item 26 & $1.51(1.1)$ & $90(76.9)$ & $7(6.0)$ & 0.45 & 0.47 & & \\
\hline Arrange & $2.02(0.9)$ & $25(21.4)$ & - & & & 0.68 & 0.69 \\
\hline Item 16 & $1.57(1.1)$ & 88 (75.2) & $6(5.1)$ & 0.23 & 0.29 & & \\
\hline Item 17 & $2.27(1.3)$ & $47(40.2)$ & $10(8.5)$ & 0.47 & 0.50 & & \\
\hline Item 18 & $2.09(1.4)$ & $63(53.8)$ & $12(10.3)$ & 0.35 & 0.53 & & \\
\hline Item 22 & $2.29(1.4)$ & $53(45.3)$ & $11(9.4)$ & 0.51 & 0.64 & & \\
\hline Item 23 & $1.88(1.3)$ & $68(58.1)$ & $7(6.0)$ & 0.61 & 0.67 & & \\
\hline
\end{tabular}

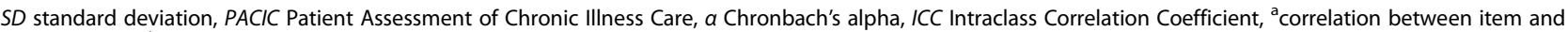
referring scale, ${ }^{b}$ correlation between item and overall PACIC score or $5 \mathrm{~A}$ summary score

factor structure convinced sufficiently. The first factor was most prominent and had an eigenvalue of 11 explaining $44 \%$ of the variation of the $5 \mathrm{~A}$ structure (PACIC: eigenvalue 8.5 and $43 \%$ explained variation). In Table 4 , the results of the factor analysis for one factor structure of the 20 PACIC items and the $255 \mathrm{~A}$ items are shown. Factor loadings were above 0.5 in $90 \%$ of the PACIC items and $88 \%$ of the $5 \mathrm{~A}$ items, supporting the one factor structure. Only item 16 had factor loadings $<0.4$ in each case.

We tested the unidimensional structures as well as Glasgow's five-factor structures via CFA. Results are shown in Table 5. Chi-squared-tests did not reach significance levels, which indicated that perfect model fit is missing. All models had values close to the cut-off value for SRMR $(\leq 0.08)$, whereby the unidimensional models reached the threshold. The model fit was not acceptable measured by the fit indices RMSEA and CFI. In summary, fit indices of CFA could confirm neither the five-factor model nor the unidimensional model with adequate fit.

\section{Discussion}

The present study aimed at evaluating the psychometric properties for the German version of the PACIC-5A questionnaire among patients with obesity in primary care. To our knowledge, this was the first study that investigated reliability and validity of the instrument used in patients with obesity. As a main result, our study showed satisfactory evidence with regard to psychometric properties of the German language version of the PACIC-5A questionnaire used in the context of obesity management.
The mean PACIC scores of previous validation studies ranged from 2.4 to $3.2[5,10]$. In comparison, our results showed a slightly lower value with 2.3 of possible 5 for overall PACIC score. The value is under the center point of the scale indicating tendencies that elements of the Chronic Care Model (CCM) are generally not met in primary care according to patient's perspective. The result for the present 5A summary score was also 2.3 of possible 5 . In contrast, Glasgow et al. revealed a comparably higher 5A summary score of 3.2 in a sample of diabetic patients and Rosemann et al. showed a value of 2.5 among patients with osteoarthritis $[10,18]$. In turn, one recently published study that used PACIC-5A among asthmatic patients in Switzerland revealed lower values of 2.0 for overall PACIC score and 5A summary score at baseline [23]. The lower scores in the present study were accompanied by high floor effects. On the one hand, high floor effects may indicate a low sensitivity range of the instrument in the lower categories [30]. On the other hand, it could represent the reality with an absence of specific elements of the CCM.

Originally, Glasgow et al. hypothesized that PACIC should not be related to patients' demographics but to disease characteristics [5]. Indeed, our study results confirmed the first part of Glasgow's hypotheses because we found no significant associations between overall PACIC score or $5 \mathrm{~A}$ summary score and patients characteristics including sex, age and education. Between the number of comorbidities and total scores we found weak positive correlation, but these results did not reach statistical significance in present study. Thus, the second part of Glasgow's hypothesis could not be confirmed based on 
A

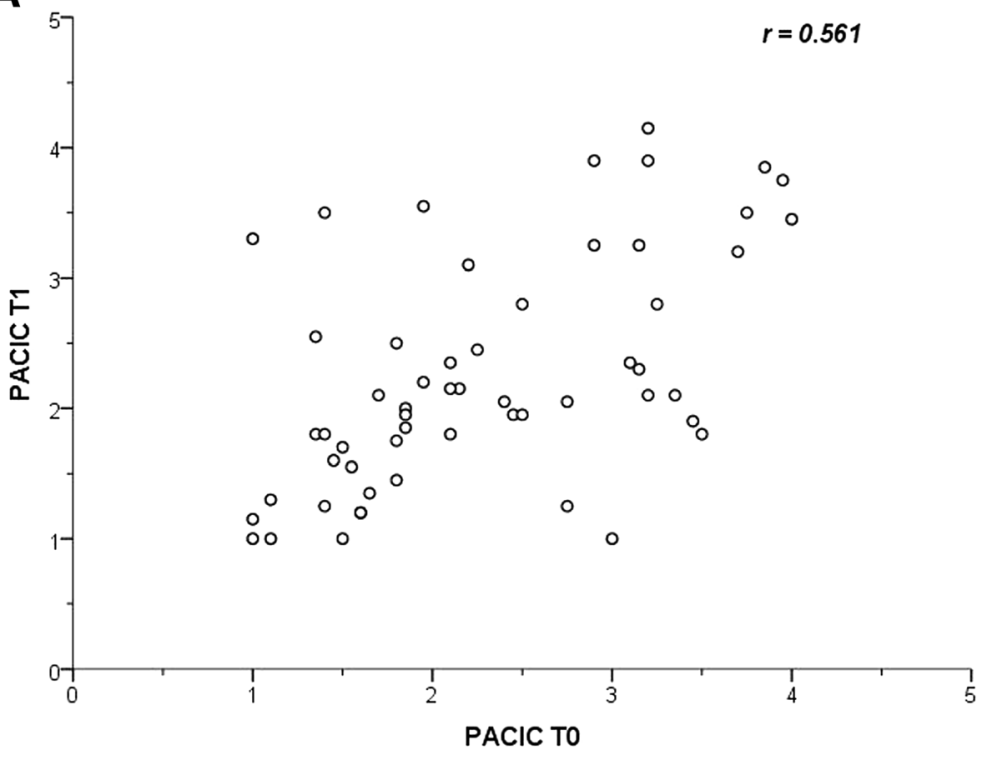

B

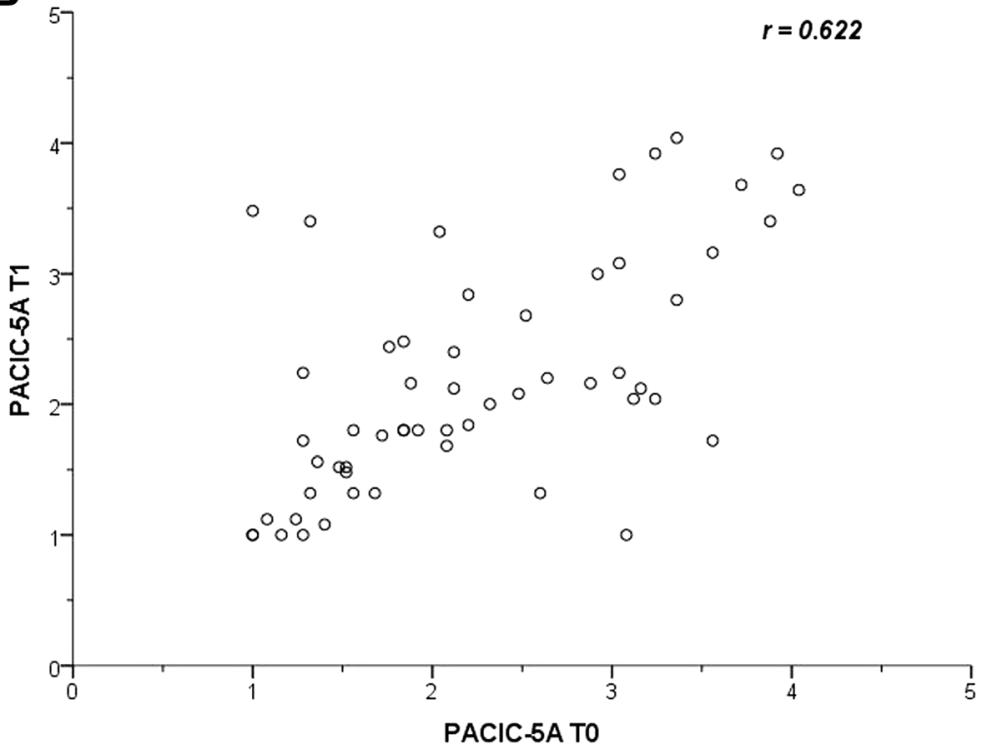

Fig. 2 Test-retest scatterplot of (a) PACIC and (b) 5A with T0 baseline measurement and T1 6-month measurement

our results. Almost all previous studies that analyzed the association between overall PACIC score and number of chronic conditions $[5,6,8,10,13,18,31]$ showed no significant or inconsistent associations. Only Glasgow et al. found weak significant correlations in one study but could not confirm these findings in another study [5, 18]. Further, some studies that used PACIC or PACIC-5A considered patients' weight for descriptive statistics [21, 32-34] and two studies investigated the correlation between BMI and PACIC-5A or PACIC short form, but they did not find significant associations $[35,36]$. Similar to these findings, we found weak negative correlations between the total scores and BMI, but the results were not significant.
Regarding internal consistency measured by Cronbach's alpha, our results were similar to others and showed high reliability values for overall PACIC and 5A summary scores. In line with previous validation studies [5, 7, 37], Cronbach's alpha for overall PACIC score was 0.93 in this study. For the 5A summary score we revealed a Cronbach's alpha of 0.94 which was slightly lower compared to the findings of Glasgow et al. (0.97) but higher than the results of Rosemann et al. $(0.83)[10,18]$. Internal consistency of the subscales also showed good reliability with values ranging from 0.7-0.9. However, the item-scale-correlations of a few items gave some reason for concern. For example, item 16 in the "Follow-up/Coordination" subscale as well as in the $5 \mathrm{~A}$ 
Table 4 Factor loadings and measure of sampling adequacy of PACIC and 5A for one-factor-structure

\begin{tabular}{|c|c|c|c|c|c|}
\hline \multirow[t]{2}{*}{ Items } & & \multicolumn{2}{|l|}{ PACIC } & \multicolumn{2}{|l|}{$5 \mathrm{~A}$} \\
\hline & & Factor loadings & KMO & Factor loadings & $\mathrm{KMO}$ \\
\hline 1 & Asked for my ideas when we made a treatment plan & 0.778 & 0.898 & 0.759 & 0.914 \\
\hline 2 & Given choices about treatment to think about & 0.719 & 0.896 & 0.709 & 0.914 \\
\hline 3 & $\begin{array}{l}\text { Asked to talk about any problems with my medicines or } \\
\text { their effects. }\end{array}$ & 0.562 & 0.905 & 0.564 & 0.923 \\
\hline 4 & Given a written list of things I should do to improve my health. & 0.530 & 0.780 & 0.493 & 0.772 \\
\hline 5 & Satisfied that my care was well organized. & 0.686 & 0.935 & & \\
\hline 6 & $\begin{array}{l}\text { Shown how what I did to take care of my illness influenced } \\
\text { my condition. }\end{array}$ & 0.642 & 0.913 & 0.618 & 0.932 \\
\hline 7 & Asked to talk about my goals in caring for my illness. & 0.792 & 0.936 & 0.785 & 0.940 \\
\hline 8 & Helped to set specific goals to improve my eating or exercise. & 0.759 & 0.931 & 0.753 & 0.912 \\
\hline 9 & Given a copy of my treatment plan. & 0.550 & 0.834 & 0.536 & 0.838 \\
\hline 10 & $\begin{array}{l}\text { Encouraged to go to a specific group or class to help me } \\
\text { cope with my chronic illness. }\end{array}$ & 0.501 & 0.886 & 0.489 & 0.814 \\
\hline 11 & $\begin{array}{l}\text { Asked questions, either directly or on a survey, about my } \\
\text { health habits. }\end{array}$ & 0.492 & 0.873 & 0.503 & 0.823 \\
\hline 12 & $\begin{array}{l}\text { Sure that my doctor or nurse thought about my values and } \\
\text { my traditions when they recommended treatments to me. }\end{array}$ & 0.829 & 0.966 & 0.847 & 0.954 \\
\hline 13 & $\begin{array}{l}\text { Helped to make a treatment plan that I could do in my } \\
\text { daily life. }\end{array}$ & 0.757 & 0.902 & 0.749 & 0.900 \\
\hline 14 & $\begin{array}{l}\text { Helped to plan ahead so I could take care of my illness even } \\
\text { in hard times. }\end{array}$ & 0.826 & 0.895 & 0.829 & 0.898 \\
\hline 15 & Asked how my chronic illness affects my life. & 0.804 & 0.927 & 0.811 & 0.932 \\
\hline 16 & Contacted after a visit to see how things were going. & 0.319 & 0.714 & 0.322 & 0.734 \\
\hline 17 & $\begin{array}{l}\text { Encouraged to attend programs in the community that } \\
\text { could help me. }\end{array}$ & 0.540 & 0.871 & 0.522 & 0.837 \\
\hline 18 & Referred to a dietitian, health educator, or counselor. & 0.577 & 0.761 & 0.562 & 0.776 \\
\hline 19 & $\begin{array}{l}\text { Told how my visits with other types of doctors, like the } \\
\text { rheumatologist or orthopedic surgeon, helped my treatment. }\end{array}$ & 0.545 & 0.790 & 0.549 & 0.803 \\
\hline 20 & Asked how my visits with other doctors were going. & 0.571 & 0.857 & 0.580 & 0.896 \\
\hline 21 & $\begin{array}{l}\text { Asked what I would like to discuss about my illness at } \\
\text { that visit. }\end{array}$ & & & 0.806 & 0.951 \\
\hline 22 & $\begin{array}{l}\text { Asked how my work, family, or social situation related to taking } \\
\text { care of my illness. }\end{array}$ & & & 0.684 & 0.894 \\
\hline 23 & $\begin{array}{l}\text { Helped to make plans for how to get support from my friends, } \\
\text { family or community. }\end{array}$ & & & 0.701 & 0.895 \\
\hline 24 & $\begin{array}{l}\text { Told how important the things I do to take care of my illness } \\
\text { (e.g. exercise) were for my health. }\end{array}$ & & & 0.771 & 0.942 \\
\hline 25 & $\begin{array}{l}\text { Set a goal together with my team for what I could do to } \\
\text { manage my condition. }\end{array}$ & & & 0.797 & 0.908 \\
\hline 26 & $\begin{array}{l}\text { Given a book or monitoring log in which to record the } \\
\text { progress I am making. }\end{array}$ & & & 0.508 & 0.900 \\
\hline
\end{tabular}

KMO Kaiser-Meyer-Olkin criterion, PACIC Patient Assessment of Chronic Illness Care

subscale "Arrange" showed correlations of 0.13 and 0.24 . Similar results are shown for the correlation between the total scores and the items. Overall, the item-total correlations were acceptable except for item 16 . However, Cronbach's alpha did not change notably if item deleted, thus we decided to keep the item in the scales. The item is already known to not fit well into the structure like mentioned in
Glasgow's validation study [5]. Indeed, it was considered as important item for follow-up scale and retained according to Glasgow et al. [5]. Based on these findings one may assume that some items do not sufficiently reflect the intended meaning of the subscale. Consequently, this should be taken into account when using the subscales and further studies are necessary. PACIC's test-retest reliability 


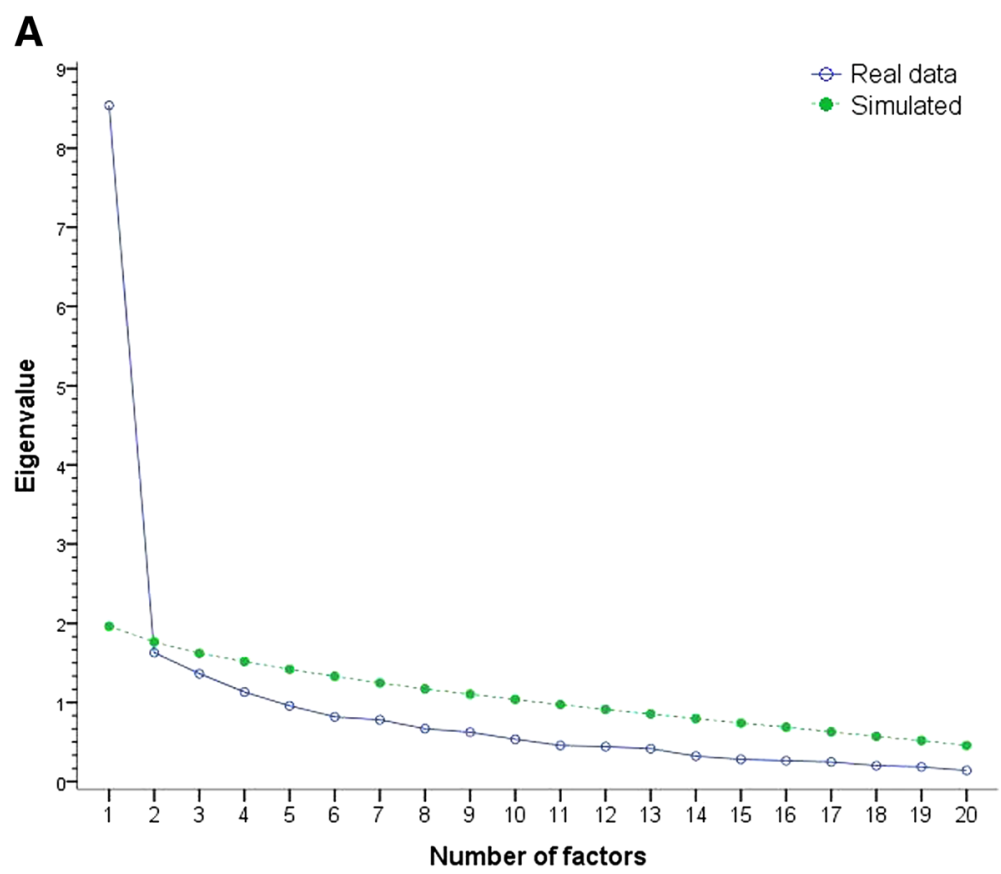

B

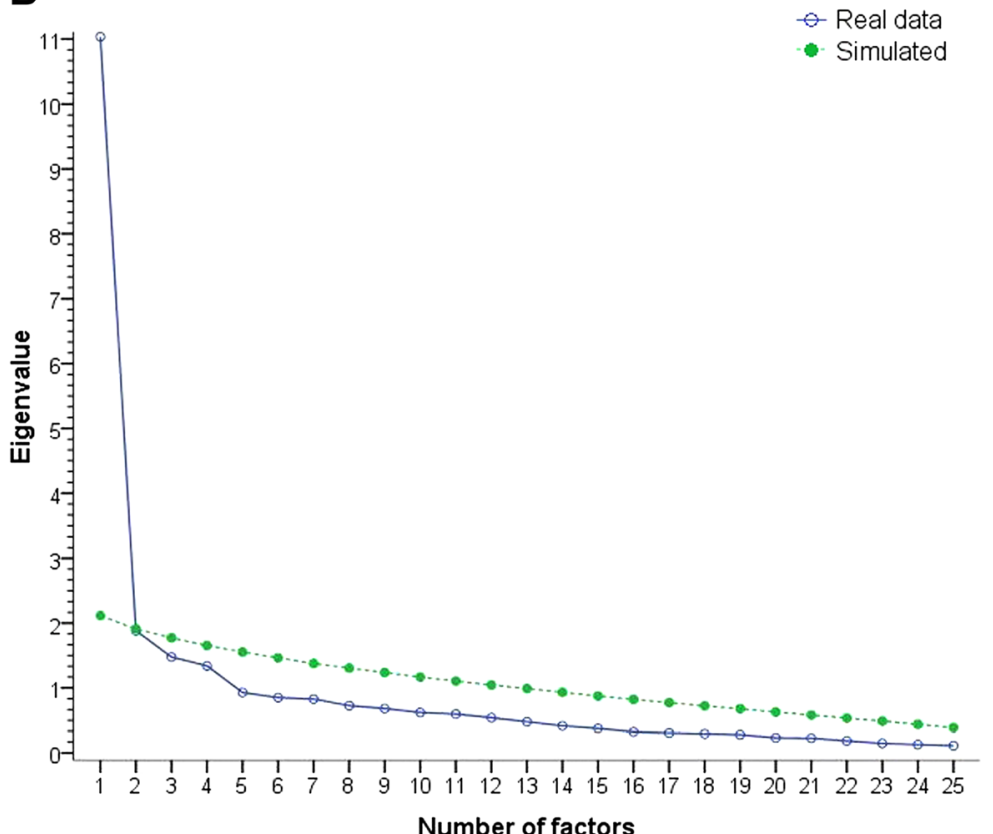

Fig. 3 Parallel analyses of (a) PACIC (20 items) and (b) 5A (25 items)

over a six-month interval was moderate and comparable to results of Glasgow's validation study (3-month test-retest reliability $=0.58)[5] .5 \mathrm{~A}$ scores demonstrated higher ICC values in our analyses and were slightly lower than in study of Rosemann et al. (2-weeks test-retest reliability $=0.88$ ) [10]. Differences could be explained by variations in the retest intervals, whereby the three-month interval is more comparable to our interval.
We found 18 studies that investigated the structure of PACIC with different methods while most of them are in accordance with present results and could not confirm the predefined five-factor structure as proposed by Glasgow et al. [5-15, 31, 32, 35, 37-40]. Three of the 18 studies found a two-factor structure by using exploratory factor analysis EFA $[9,12,13]$ and one study conducted an EFA with best fit for four-factor structure with a 
Table 5 Model fit of the Confirmatory Factor Analyses $(N=117)$

\begin{tabular}{llllll}
\hline & \multicolumn{1}{l}{ PACIC } & & 5A & \\
\cline { 2 - 3 } & 1 -factor model & 5 -factor model & & 1-factor model & 5-factor model \\
\hline$X^{2}(\mathrm{df})$ & $402.01(170)$ & $322.78(160)$ & $632.07(275)$ & $606.82(265)$ \\
$p$-value & $<0.001$ & $<0.001$ & $<0.001$ & $<0.001$ \\
CFI & 0.805 & 0.863 & 0.792 & 0.801 \\
RMSEA (90\% Cl) & $0.108(0.094-0.122)$ & $0.093(0.079-0.108)$ & $0.105(0.095-0.116)$ & $0.105(0.094-0.116)$ \\
SRMR & 0.080 & 0.082 & 0.079 & 0.083 \\
\hline
\end{tabular}

$d f$ degrees of freedom, CFI Comparative Fit Index, RMSEA Root Mean Square Error of Approximation, Cl confidence interval, SRMR Standardized Root Mean Residual

prominent first factor that included more than half of all items [15]. Furthermore, eight of the 18 studies suggested a one-factor structure and use of the overall PACIC score [11, 14, 31, 32, 35, 37-39]. Three of the eight studies used EFA partly with parallel analysis (PA), which was similar to our investigation [11, 32, 38]. One of the eight studies applied principal component analysis (PCA) but had a look only on the PACIC short form [39] and two studies used confirmatory factor analysis (CFA) and showed acceptable to good fit for PACIC and PACIC short form [35, 37]. Moreover, two of the eight studies tested different structure models via CFA including the predefined five-factor structure but none had acceptable model fit $[14,31]$, which is in line with present CFA results. Therefore, the authors recommended the calculation and use of the overall PACIC score. In contrast to our results and mentioned studies, Glasgow et al. developed and confirmed their predefined five-factor model by CFA with moderate fit [5]. Further five studies among the 18 studies suggested also a five-factor structure, whereby the results were not throughout uniform and not always equal to the originally developed structure. One study that used PCA confirmed only three of the five predefined subscales [7]. Another study used CFA and reported poor fit for four indices and good fit for two indices [8]. Two studies that used EFA confirmed Glasgow's five-factor structure but did not provide detailed information about analysis strategy and results $[6,10]$. Noël et al. used EFA and CFA to identify a five-factor structure but the distribution was different from the predefined suggestion [40]. In summary, many studies evaluated the structure of PACIC but there is conflicting evidence. Overall, most of the studies suggested a one- to two-factor structure which goes in hand with the present results for EFA. The statistical methods between the studies were quiet different and studies that conducted EFA used different methods to estimate the number of factors. We used EFA with PA as well as eigenvalue criterion and scree plot. Decisive was the PA because it is one of the most accurate methods [27, 41]. Contrary to the PA, the scree-plot is more subjective and the eigenvalue criterion often overestimates the number of factors, thus these criteria are assumed to be less exactly than PA $[27,41]$.
In contrast to the numerous studies on the PACIC structure, only one previous study investigated the structure of PACIC-5A. Although Glasgow et al. defined the 5A subscales according to the US Preventive Services Task Force and developed PACIC-5A, they did not evaluate the underlying structure. Only Rosemann et al. investigated and confirmed the structure of the 5A concept of PACIC-5A via EFA but little is known about the analytic and detailed results [10]. In our analysis, the five proposed subscales of the $5 \mathrm{~A}$ construct could not be confirmed by confirmatory and exploratory factor analyses. Thus, more investigations are necessary to confirm the 5As in PACIC-5A among different patient samples.

In summary, we could not confirm Glasgow's 5-factor structure for PACIC and 5A. Our exploratory factor analyses resulted in one-factor solutions according to PA and scree-plot. Furthermore, one fit index of conducted CFA reached the threshold for the one-factor structure. Thus, in line with previous studies $[11,14,31,32,37]$ we recommend the use of the total scores to assess patient-providers interactions. However, it must be mentioned that other CFA indices showed poor fit.

It is important to note that the present study had some limitations. First, our study had a sample size of 117 persons which is rather in the lower range compared with other PACIC validation studies. It has to be mentioned that fit indices of CFA are vulnerable for small sample sizes and tend to over-reject models, thus $\mathrm{Hu}$ and Bentler recommended samples with more than 250 subjects [28]. Second, PACIC was measured via ordinal 5-point Likert scale though we used the scales like metric variables. Some PACIC validation studies criticized that the ordinal nature of the data is often not considered [11, 14], but a condition that a Likert scale could trait as "quasi-metric" is that there are at least five scale categories, what is given in the used PACIC-5A questionnaire [42, 43]. However, our analyses showed similar results like studies that took the ordinal structure into account [32, 35, 38]. Third, we were not able to analyze other aspects of reliability and validity such as criterion validity based on our data. However, no accepted gold standard instrument is available for comparison.

The reimbursement system of the health insurances in Germany covers illnesses which occur subsequently or 
are associated with obesity but not obesity as a single disease entity [44]. This aspect could be a further explanation for the low mean values of PACIC-5A in present study and calls for optimization of obesity care in Germany. In accordance, the WHO declared obesity as disease since 2000 [29] and in 2011 the European Parliament urged the uniform approval of obesity as chronic condition for adequate treatment and prevention [45].

\section{Conclusions}

In conclusion, the results provide substantial evidence regarding the psychometric properties of the German version of the PACIC-5A as practicable instrument for the assessment of primary care structure and self-management support in obesity from patient's perspective. Further studies should preferably use the overall scores. The subscales should be viewed with caution and may be useful for comparison in follow-up examinations with additional consideration of the underlying structure. Altogether, the present study makes an important contribution to the reliable and valid assessment of the patient-GP interaction with regard to obesity counseling in primary care.

\section{Additional file}

Additional file 1: Table S1. Factor loadings for PACIC (promax rotation) - four-factor model. Table S2. Factor loadings for 5A (promax rotation) four-factor model. (DOCX $20 \mathrm{~kb}$ )

\section{Abbreviations}

BL: Baseline Assessment; BMI: Body Mass Index; CCM: Chronic Care Model; CFA: Confirmatory Factor Analysis; CFI: Comparative Fit Index; EFA: Exploratory Factor Analysis; FU: Follow-Up; GP: General Practitioners; ICC: Intraclass Correlation Coefficient; KMO: Kaiser-Meyer-Olkin-Criterion; PA: Parallel Analysis; PACIC: Patient Assessment of Chronic Illness Care; PCA: Principal Component Analysis; RMSEA: Root Mean Square Error of Approximation; SRMR: Standardized Root Mean Square Residuals; WHO: World Health Organization

\section{Acknowledgments}

We acknowledge support from the German Research Foundation (DFG) and Leipzig University within the program of Open Access Publishing. This work was supported by the Federal Ministry of Education and Research (BMBF), Germany, (Integrated Research and Treatment Center (IFB) AdiposityDiseases, FKZ: 01EO1501).

\section{Funding}

This work was supported by the Federal Ministry of Education and Research (BMBF), Germany, FKZ: 01EO1501. The funder had no role in the design of the study, nor in the collection, analysis, and interpretation of the data and in writing the manuscript.

\section{Availability of data and materials}

The datasets generated and analyzed during the current study are not publicly available due ethical restrictions and patient confidentiality but are available from the corresponding author on reasonable request. Aggregated data are provided in the paper tables.

\section{Authors' contributions}

MS conception, design, analysis and interpretation of data, drafting the manuscript, revising manuscript, final approval; FW acquisition of data, project administration, revising manuscript, final approval; AP formal analysis, revising manuscript, final approval; CLS, AK, MB, HHK conception, revising manuscript, final approval; SRH conception, design, funding acquisition, revising manuscript, final approval; JS conception, design, project administration, revising manuscript, final approval. All authors read and approved the final manuscript.

\section{Ethics approval and consent to participate}

The ethics committee of the University of Leipzig has approved this study (AZ:: 248-15-13,072,015). The study was performed in accordance with the Guidelines for Good Clinical Practice (ICH-GCP), the Declaration of Helsinki in its latest version and international and local laws. Written informed consent was obtained from all participants prior to enrolment in the study.

Consent for publication

Not applicable.

\section{Competing interests}

The authors declare that they have no competing interests.

\section{Publisher's Note}

Springer Nature remains neutral with regard to jurisdictional claims in published maps and institutional affiliations.

\section{Author details}

${ }^{1}$ Institute of Social Medicine, Occupational Health and Public Health, Medical Faculty, University of Leipzig, Leipzig, Germany. ${ }^{2}$ Integrated Research and Treatment Centre (IFB) AdiposityDiseases, University of Leipzig, Leipzig, Germany. ${ }^{3}$ SRH University of Applied Sciences, Gera, Germany. ${ }^{4}$ Department of Psychosomatic Medicine and Psychotherapy, University of Leipzig, Leipzig, Germany. ${ }^{5}$ Department of Health Economics and Health Services Research, University Medical Center Hamburg-Eppendorf, Hamburg, Germany. ${ }^{6}$ Institute of General Medicine, University of Leipzig, Leipzig, Germany.

Received: 17 July 2018 Accepted: 4 January 2019

Published online: 23 January 2019

\section{References}

1. WHO. Obesity and overweight; 2016. Available: http://www.who.int/ mediacentre/factsheets/fs311/en/. Accessed 16 June 2018.

2. WHO. Global status report on noncommunicable diseases 2010. Geneva: World Health Organization; 2011.

3. Wagner EH, Austin BT, von Korff M. Organizing care for patients with chronic illness. Milbank Q. 1996;74:511-44.

4. Wagner EH, Austin BT, Davis C, Hindmarsh M, Schaefer J, Bonomi A. Improving chronic illness care. Translating evidence into action. Health Aff (Millwood). 2001;20:64-78. https://doi.org/10.1377/hlthaff.20.6.64.

5. Glasgow RE, Wagner EH, Schaefer J, Mahoney LD, Reid RJ, Greene SM. Development and validation of the patient assessment of chronic illness care (PACIC). Med Care. 2005;43:436-44. https://doi.org/10.1097/01.mlr. $0000160375.47920 .8 \mathrm{C}$.

6. Aragones A, Schaefer EW, Stevens D, Gourevitch MN, Glasgow RE, Shah NR. Validation of the Spanish translation of the patient assessment of chronic illness care (PACIC) survey. Prev Chronic Dis. 2008;5:A113.

7. Wensing M, van Lieshout J, Jung HP, Hermsen J, Rosemann T. The patients assessment chronic illness care (PACIC) questionnaire in the Netherlands: a validation study in rural general practice. BMC Health Serv Res. 2008;8:182. https://doi.org/10.1186/1472-6963-8-182.

8. Maindal HT, Sokolowski I, Vedsted P. Adaptation, data quality and confirmatory factor analysis of the Danish version of the PACIC questionnaire. Eur J Pub Health. 2012;22:31-6. https://doi.org/10.1093/ eurpub/ckq188.

9. Krucien N, Le Vaillant M, Pelletier-Fleury N. Adaptation and validation of the patient assessment of chronic illness care in the French context. BMC Health Serv Res. 2014;14:269. https://doi.org/10.1186/1472-6963-14-269.

10. Rosemann T, Laux G, Droesemeyer S, Gensichen J, Szecsenyi J. Evaluation of a culturally adapted German version of the patient assessment of chronic illness care (PACIC 5A) questionnaire in a sample of osteoarthritis patients. J Eval Clin Pract. 2007;13:806-13. https://doi.org/10.1111/j.1365-2753.2007. 00786.x. 
11. Gugiu C, Coryn CLS, Applegate B. Structure and measurement properties of the patient assessment of chronic illness care instrument. J Eval Clin Pract. 2010;16:509-16. https://doi.org/10.1111/j.1365-2753.2009.01151.x.

12. Taggart J, Chan B, Jayasinghe UW, Christl B, Proudfoot J, Crookes $P$, et al. Patients assessment of chronic illness care (PACIC) in two Australian studies: structure and utility. J Eval Clin Pract. 2011;17:215-21. https://doi.org/10. 1111/j.1365-2753.2010.01423.x.

13. Gensichen J, Serras A, Paulitsch MA, Rosemann T, Konig J, Gerlach FM, et al. The patient assessment of chronic illness care questionnaire: evaluation in patients with mental disorders in primary care. Community Ment Health J. 2011;47:447-53. https://doi.org/10.1007/s10597-010-9340-2.

14. Drewes HW, Jong-van Til JT d, Struijs JN, Baan CA, Tekle FB, Meijboom BR, et al. Measuring chronic care management experience of patients with diabetes. PACIC and PACIC+ validation. Int J Integr Care. 2012;12:e194.

15. Fan J, McCoy RG, Ziegenfuss JY, Smith SA, Borah BJ, Deming JR, et al. Evaluating the structure of the patient assessment of chronic illness care (PACIC) survey from the patient's perspective. Ann Behav Med. 2015;49:10411. https://doi.org/10.1007/s12160-014-9638-3.

16. Goldstein MG, Whitlock EP, DePue J. Multiple behavioral risk factor interventions in primary care. Summary of research evidence Am J Prev Med. 2004;27:61-79. https://doi.org/10.1016/j.amepre.2004.04.023.

17. Whitlock E. Evaluating primary care behavioral counseling interventions an evidence-based approach. Am J Prev Med. 2002;22:267-84. https://doi.org/ 10.1016/S0749-3797(02)00415-4

18. Glasgow RE, Whitesides H, Nelson CC, King DK. Use of the patient assessment of chronic illness care (PACIC) with diabetic patients. Relationship to patient characteristics, receipt of care, and self-management. Diabetes Care. 2005;28:2655-61. https://doi.org/10.2337/diacare.28.11.2655.

19. Serdula MK, Khan LK, Dietz WH. Weight loss counseling revisited. JAMA. 2003;289:1747-50. https://doi.org/10.1001/jama.289.14.1747

20. Frei A, Chmiel C, Schläpfer H, Birnbaum B, Held U, Steurer J, et al. The chronic CARe for diAbeTes study (CARAT). A cluster randomized controlled trial. Cardiovasc Diabetol. 2010;9:23. https://doi.org/10.1186/1475-2840-9-23.

21. Gijs E, Zuercher E, Henry V, Morin D, Bize R, Peytremann-Bridevaux I. Diabetes care: comparison of patients' and healthcare professionals' assessment using the PACIC instrument. J Eval Clin Pract. 2017. https://doi. org/10.1111/jep.12720.

22. Dürr $\mathrm{S}$, Hersberger KE, Zeller A, Scheuzger J, Miedinger D, Gregoriano C, et al. The integrated care of asthma in Switzerland (INCAS)-study. Patients' perspective of received asthma care and their interest in asthma education. J Asthma. 2016;53:955-63. https://doi.org/10.3109/02770903.2016.1170140.

23. Dürr S, Hersberger KE, Zeller A, Scheuzger J, Miedinger D, Gregoriano C, et al. The integrated Care of Asthma in Switzerland (INCAS) study. Changes in asthma control and perception of health care through asthma education. Respiration. 2017;94:416-23. https://doi.org/10.1159/000478945.

24. Welzel FD, Stein J, Pabst A, Luppa M, Kersting A, Blüher M, et al. Five A's counseling in weight management of obese patients in primary care. A cluster-randomized controlled trial (INTERACT). BMC Fam Pract. 2018;19:97. https://doi.org/10.1186/s12875-018-0785-7.

25. Brauns H, Steinmann S. Educational reform in France, West-Germany and the United Kingdom : updating the CASMIN educational classification. ZUMA Nachrichten 1999: 7.

26. Tavakol M, Dennick R. Making sense of Cronbach's alpha. Int J Med Educ. 2011;2:53-5. https://doi.org/10.5116/ijme.4dfb.8dfd.

27. O'Connor BP. SPSS and SAS programs for determining the number of components using parallel analysis and Velicer's MAP test. Behav Res Methods Instrum Comput. 2000;32:396-402. https://doi.org/10.3758/ BF03200807.

28. $\mathrm{Hu}$ L, Bentler PM. Cutoff criteria for fit indexes in covariance structure analysis. Conventional criteria versus new alternatives Structural Equation Modeling: A Multidisciplinary Journal. 1999;6:1-55. https://doi.org/10.1080/ 10705519909540118.

29. WHO. Obesity. Preventing and managing the global epidemic. Report of a WHO consultation World Health Organ Tech Rep Ser 2000; 894: i-xii, 1-253.

30. Döring N, Bortz J. Forschungsmethoden und Evaluation in den Sozial- und Humanwissenschaften. Berlin, Heidelberg: Springer Berlin Heidelberg; 2016.

31. Rick J, Rowe K, Hann M, Sibbald B, Reeves D, Roland M, et al. Psychometric properties of the patient assessment of chronic illness care measure: acceptability, reliability and validity in United Kingdom patients with longterm conditions. BMC Health Serv Res. 2012;12:293. https://doi.org/10.1186/ 1472-6963-12-293.
32. Aung E, Ostini R, Dower J, Donald M, Coll JR, Williams GM, et al. Patient assessment of chronic illness care (PACIC) in type 2 diabetes: a longitudinal study. Eval Health Prof. 2014;39:185-203. https://doi.org/10.1177/ 0163278714556674.

33. Szecsenyi J, Rosemann T, Joos S, Peters-Klimm F, Miksch A. German diabetes disease management programs are appropriate for restructuring care according to the chronic care model: an evaluation with the patient assessment of chronic illness care instrument. Diabetes Care. 2008;31:11504. https://doi.org/10.2337/dc07-2104.

34. Aung E, Donald M, Williams GM, Coll JR. SAR. Influence of patient-assessed quality of chronic illness care and patient activation on health-related quality of life. Int J Qual Health Care. 2016;28:306-10. https://doi.org/10. 1093/intqhc/mzw023.

35. Iglesias K, Burnand B, Peytremann-Bridevaux I. PACIC instrument: disentangling dimensions using published validation models. Int J Qual Health Care. 2014;26:250-60. https://doi.org/10.1093/intqhc/mzu042.

36. Rosemann T, Laux G, Szecsenyi J, Grol R. The chronic care model: congruency and predictors among primary care patients with osteoarthritis. Qual Saf Health Care. 2008;17:442-6. https://doi.org/10.1136/qshc.2007. 022822.

37. Cramm JM, Nieboer AP. Factorial validation of the patient assessment of chronic illness care (PACIC) and PACIC short version (PACIC-S) among cardiovascular disease patients in the Netherlands. Health Qual Life Outcomes. 2012;10:104. https://doi.org/10.1186/1477-7525-10-104.

38. Gugiu PC, Coryn C, Clark R, Kuehn A. Development and evaluation of the short version of the patient assessment of chronic illness care instrument. Chronic IIIn. 2009;5:268-76. https://doi.org/10.1177/1742395309348072.

39. Goetz K, Freund T, Gensichen J, Miksch A, Szecsenyi J, Steinhaeuser J. Adaptation and psychometric properties of the PACIC short form. Am J Manag Care. 2012;18:e55-60.

40. Noël PH, Jones S, Parchman ML. Patient experience in an era of primary care transformation. Revisiting the PACIC Eur J Pers Cent Healthc. 2014;4: 528-40.

41. Hayton JC, Allen DG, Scarpello V. Factor retention decisions in exploratory factor analysis. A tutorial on parallel analysis. Organ Res Methods. 2016;7: 191-205. https://doi.org/10.1177/1094428104263675.

42. Bartholomew DJ, Steele F, Galbraith J, Moustaki I. Analysis of multivariate social science data, second edition: CRC Press; 2008.

43. Urban D, Mayerl J. Regressionsanalyse. Theorie, Technik und Anwendung: VS Verlag für Sozialwissenschaften; 2011.

44. Klein S, Krupka S, Behrendt S, Pulst A, Bleß H. Weißbuch Adipositas. Versorgungssituation in Deutschland. Berlin: Medizinisch Wissenschaftliche Verlagsgesellschaft; 2016.

45. Europäisches Parlament. Abbau gesundheitlicher Ungleichheit in der EU P7_TA(2011)0081. Entschließung des Europäischen Parlaments vom 8. März 2011 zu dem Abbau gesundheitlicher Ungleichheit in der EU (2010/ 2089(INI)); 2011. Available: http://www.europarl.europa.eu/sides/getDoc. do?pubRef=-//EP//TEXT+TA+P7-TA-2011-0081+0+DOC+XML+V0//DE. Accessed 17 May 2018.
Ready to submit your research? Choose BMC and benefit from:
- fast, convenient online submission
- thorough peer review by experienced researchers in your field
- rapid publication on acceptance
- support for research data, including large and complex data types
- gold Open Access which fosters wider collaboration and increased citations
- maximum visibility for your research: over $100 \mathrm{M}$ website views per year
At BMC, research is always in progress. 